\title{
Expression of Retroviral Transduced Human CD18 in Murine Cells: An In Vitro Model of Gene Therapy for Leukocyte Adhesion Deficiency
}

\author{
J.C. KRAUSS, ${ }^{1}$ L.M. BOND,${ }^{1}$ R.F. TODD III, ${ }^{1}$ and J.M. WILSON ${ }^{1,2}$
}

\begin{abstract}
Leukocyte adhesion deficiency (LAD) is an autosomal recessive disease caused by a defective CD18 gene. The cell-surface glycoprotein encoded by this gene CD18 is normally expressed in cells of the hematopoietic system. An in vitro murine model of CD18 gene replacement therapy was developed to investigate the feasibility of an in vivo murine hematopoietic stem cell gene therapy model. Human CD18-transducing retroviruses were used to transfer a functional human $\mathrm{CD18}$ gene into a variety of cells including (i) murine lymphoblasts (which express murine CD11a and murine CD18), (ii) murine fibroblasts (which have no endogenous murine CD11a/CD18 expression), and (iii) murine fibroblasts, which have been stably transfected with a human CD11a gene. In murine lymphoblasts, human CD18 was expressed on the cell surface as a heterodimer with murine CD11a. Cell-surface expression of human CD18 had no apparent effect on the level of endogenous murine CD11a/CD18 expression. Immunoprecipitation of cell-surface labeled proteins in murine lymphoblasts with a human CD18 specific antibody co-precipitated murine CD11a. Human CD18 can be detected by immunochemistry in the cytoplasm of fibroblasts infected with CD18 encoding retrovirus, but coexpression with CD11a is required for cell-surface expression of either subunit in fibroblasts. These studies suggest that human CD18 will form a heterodimer with murine CD11a and that human CD18 is not expressed on the cell surface of cells not expressing CD11. This provides the basis for the development of a murine hematopoietic stem cell gene replacement therapy model for the treatment of LAD.
\end{abstract}

\section{OVERVIEW SUMMARY}

In developing human gene therapy clinical protocols, it is helpful to have an animal model that mimics the human disease to be treated. A natural animal model for leukocyte adhesion deficiency (LAD) does not exist. Krauss et al. have developed a clever strategy for producing a mouse model for LAD gene therapy.

\section{INTRODUCTION}

$\mathbf{L}$ EUKOCYTE ADHESION DEFICIENCY (LAD) is a rare, autosomal recessive disorder characterized by recurrent infections and absence of leukocyte adherence to a variety of surfaces
(Anderson and Springer, 1987; Todd and Freyer, 1988). Normal leukocyte adhesion is mediated by a series of heterodimeric, transmembrane glycoproteins composed of a common $\beta$-subunit $\mathrm{CD} 18$ and one of three unique $\alpha$-subunits CD11a, CD11b, and CD11c (Springer et al., 1984). In LAD patients, a defective $\mathrm{CD} 18$ gene results in absent or decreased cell-surface expression of CD1 1/CD18 dimers (Springer et al., 1984). Severely affected patients (patients with CD11/CD18 levels of less than $1 \%$ of normal level) succcumb to severe infections in early childhood (Anderson et al., 1985). The disorder is characterized by peripheral leukocytosis, but virtually no pus formation at the site of infection, indicating that deficient CD11/CD18 neutrophils may not properly migrate to areas of active infection (Anderson et al., 1985). Bone marrow transplantation is curative, suggesting that reconstitution of CD18 expression in the hematopoietic

\footnotetext{
${ }^{1}$ Departments of Internal Medicine and ${ }^{2}$ Biological Chemistry, and ${ }^{2}$ Howard Hughes Medical Institute, University of Michigan, Ann Arbor, MI 48109-0650.
} 
stem cell may be therapeutic (Le Deist et al., 1989).

We and others have shown that retroviral mediated transduction of a human CD18 gene can complement the defect in a lymphoblast cell line derived from a patient with a LAD (Back $e t$ al., 1990; Wilson et al., 1990). Because the defect is manifested in both lymphocytes and granulocytes, the hematopoietic stem cell is the appropriate cell to correct in this disorder (Todd and Freyer, 1988). We ultimately seek to develop a murine bone marrow transplant model of a stem cell gene replacement therapy of LAD.

Our strategy for developing an in vivo animal model of LAD gene therapy is to introduce a normal human CD18 gene into bone marrow of a wild-type mouse, and reconstitute a syngeneic recipient with the vector-transduced bone marrow. An important feature of this model is a method for detecting human CD18 expression in murine leukocytes. In addition, the potential for ectopic CD18 cell-surface expression needs to be addressed.

In this report, we use a murine T-lymphoblast cell line (which normally expresses murine CD11a/CD18) to develop a specific and sensitive assay for detecting human $\mathrm{CD} 18$ on the cell surface of murine leukocytes. The assay is based on the hypothesis that human CD18 will form chimeric heterodimers with murine CD11 on the surface and that the human subunit can be detected with human specific monoclonal antibodies (mAbs). Additional experiments were aimed at studying human CD18 expression in nonhematopoietic cells in the presence or absence of CD11 expression.

\section{MATERIALS AND METHODS}

Cell Lines: BW5147 was derived from a murine T-cell lymphoma (Ralph, 1973) and obtained from the American Type Culture Collection (ATCC; Rockville, MD). $\Psi$ cre (Danos and Mulligan, 1988) and NIH-3T3 cells were obtained from $\mathbf{R}$. Mulligan (Whitehead Institute, Boston, MA). All lymphoblast populations were grown in DMEM (high glucose) supplemented with $10 \%$ fetal bovine serum (GIBCO, Grand Island, NY) and penicillin/streptomycin. $\Psi_{\mathrm{cre}}$ and NIH-3T3 cells were grown in DMEM (high glucose) supplemented with $10 \%$ calf serum and penicillin/streptomycin.

NIH-3T3 Cell Line That Expresses Human CD11a: A vector that expresses human CD11a was constructed. Sequences spanning the entire coding region of human CD11a were excised on a Hind III to $S p h$ I fragment of the previously described cDNA clone, pLAR (provided by Dr. T. Springer, Boston, MA; Larson et al., 1989). The $S p h$ I site was converted to an Xba I site with synthetic linkers and the modified fragment was ligated with a

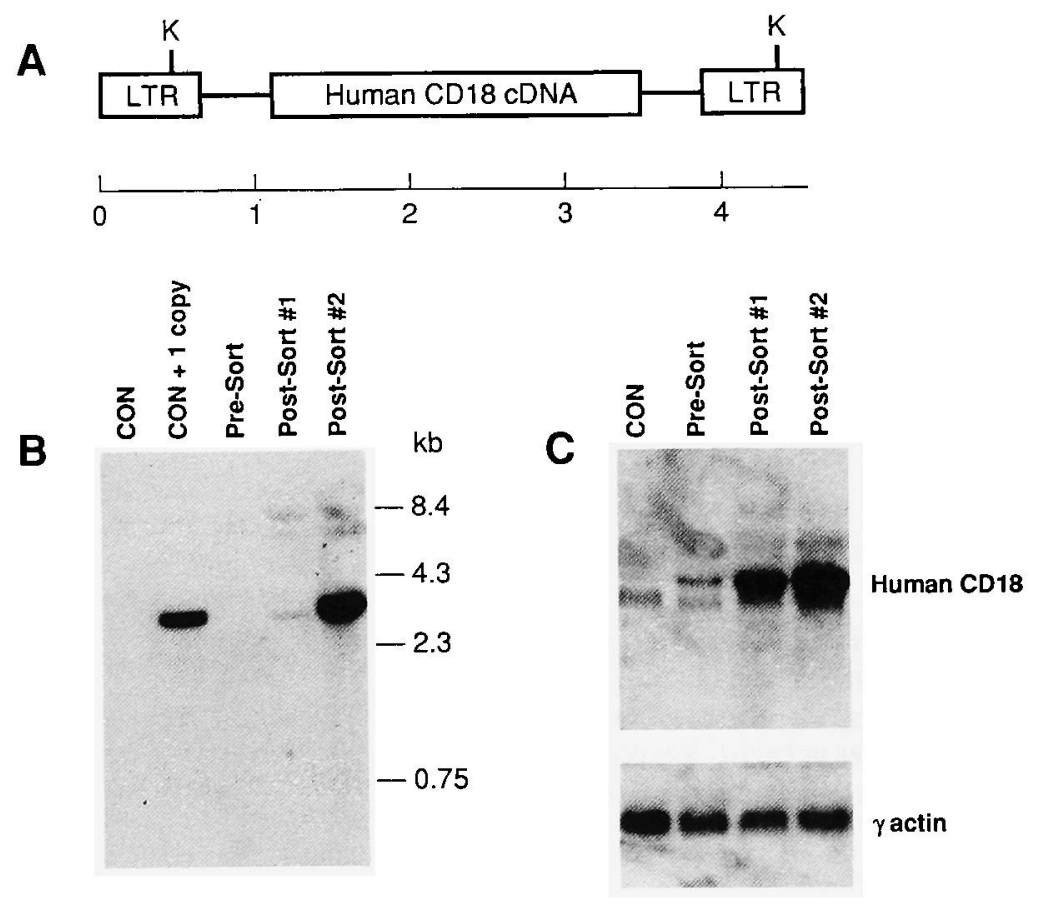

FIG. 1. A. Structure of pEMO-CD18 retroviral vector. LTR, Long terminal repeat sequences; K, Kpn I. B. DNA blot analysis. Total cellular DNA $(10 \mu \mathrm{g})$ was restricted with $K p n$ I and analyzed as described in Materials and Methods. DNA (10 $\mu \mathrm{g})$ from untransduced BW5147 cells was analyzed alone (CON) and with the equivalent of one copy of provirus/cell (7.5 pg) of pEMO-CD18 plasmid (CON + 1 copy). Analyses were also performed with DNA from BW5147 cells after co-cultivation prior to FACS (Pre-Sort), and after one round (Post-Sort \#1) and two rounds (Post-Sort \#2) of FACS. Molecular weight markers are listed along the right border. C. RNA blot analysis. Total cellular RNA $(10 \mu \mathrm{g})$ was analyzed as described in Materials and Methods. RNA was isolated from untransduced BW5147 cells (CON) and transduced BW5147 cells prior to FACS (Pre-Sort), and after one round (Post-Sort \#1) and two rounds (Post-Sort \#2) of FACS. The filter was initially probed with a radiolabeled CD18 cDNA fragment (upper radiograph). The band at $3 \mathrm{~kb}$ is common to all lanes and represents hybridization to the endogenous transcript. The filter was stripped and reprobed with the radiolabeled fragment from human $\gamma$-actin gene (lower audioradiograph; Wilson et al., 1988). 
Hind III/Xba I fragment from the expression vector called pBA. This vector contains a promoter derived from the chicken $\beta$-actin gene ( -274 to $+1 \mathrm{bp}$; Quitschke et al., 1989) and polyadenylation sequences from bovine growth hormone. This plasmid, called pBA-hCD11a $(10 \mu \mathrm{g})$ was mixed with pSV2Neo and transfected into NIH-3T3 cells (Danos and Mulligan, 1988). The cells were allowed to come to confluence and then split into DMEM containing G418 (1 mg/ml total concentration). Fifteen individual clones of G418-resistant cells were selected and scaled up into duplicate $10-\mathrm{cm}$ plates; cells from one plate were cryopreserved and the other was used to make RNA. The individual clones were screened for content of human CD11a RNA, and the clone that produced the highest levels of CD11a RNA was scaled up, and transduced with the CD18 encoding retroviral vector as described for NIH-3T3 cells.

Retroviral Vectors and Transduction: The retroviral vector pEMO-CD18 has been described (Wilson et al., 1990). A $\Psi$ cre packaging cell line was produced from this vector as follows: pEMO-CD18 plasmid DNA $(15 \mu \mathrm{g})$ was co-transfected with pSV2NEO $(1.5 \mu \mathrm{g})$ as described by Danos and Mulligan (1988). After the transfected populations of cells had come to confluence, they were split into medium containing G418 $(1 \mathrm{mg} / \mathrm{ml}$ total concentration). Twenty-five individual G418-resistant colonies were isolated and cryopreserved. Tissue culture supernatant from each of the expanded clones was harvested and the titer of virus in each supernatant was estimated as follows. NIH-3T3 cells at $10^{6}$ cells $/ 10-\mathrm{cm}$ plate were transduced with retroviral vector supernatant in the presence of $8 \mu \mathrm{g} / \mathrm{ml}$ of Polybrene for 12-16 hr. When the monolayers were confluent, high-molecular-weight DNA was isolated, restricted with $K p n \mathrm{I}$, and assayed by DNA blot analysis using human CD18 as a probe. This permits an analysis of proviral integrity and estimate of proviral abundance in the transduced cells. The clone capable of producing the highest titer of vector, as measured by the most abundant quantity of unrearranged provirus in the transduced NIH-3T3 cells, was used in subsequent experiments.

The recombinant retroviral vector producing clone (initial density $1.2 \times 10^{6}$ cells $/ 10$-cm plate) was cocultivated with the murine lymphoblast BW5147 $\left(5 \times 10^{6}\right.$ cells $)$ in DMEM containing fetal calf serum (10\%), penicillin/streptomycin, and Polybrene $(8 \mu \mathrm{g} / \mathrm{ml})$ for 2 days. Following the co-cultivation, the lymphoblasts were gently removed by serially plating the cells into two tissue cultures flasks (Falcon) for a total of $48 \mathrm{hr}$. The lymphoblasts were then expanded and analyzed.

Immunochemistry: Retroviral vector-transduced and -transfected NIH-3T3 fibroblasts were analyzed for expression of human CD11a and CD18 by immunocytochemistry. The transduced cells were plated onto glass slides, fixed in ethanol for 10 min at $4^{\circ} \mathrm{C}$, incubated with a mAb (either anti-human-CD11a [TS1/22], or anti-human-CD18 [TS1/18]), washed, and then secondarily stained with goat anti-murine immunoglobulinbiotin conjugate. The slides were then washed and stained with a streptavidin-horseradish peroxidase conjugate and developed with 9-AEC purchased from Zymed labs (San Francisco, CA). TS1/18 and TS $1 / 22$ used in this experiment were obtained from the ATCC and used as neat tissue culture supernatants (SanchezMadrid et al., 1982).

Flow Cytometric Analysis: Rat anti-murine CD11a (M17/ 4.4.11.9; Sanchez-Madrid et al., 1983), rat anti-murine CD18 (M18-2.a.12.7; Sanchez-Madrid et al., 1983), and the murine control antibody [rat anti-murine CD11b(M1/70.15.11.5.HL; Springer et al., 1978)] were from the ATCC and were used as neat tissue culture supernatants. The murine anti-human CD18 antibody (IB4) was kindly provided in a purified form by Dr. S. Wright (Rockefeller University, New York, NY; Wright et al., 1983). Murine anti-human control antibodies M45q and P181 were purified from ascites (Biondi et al., 1984). Single-color
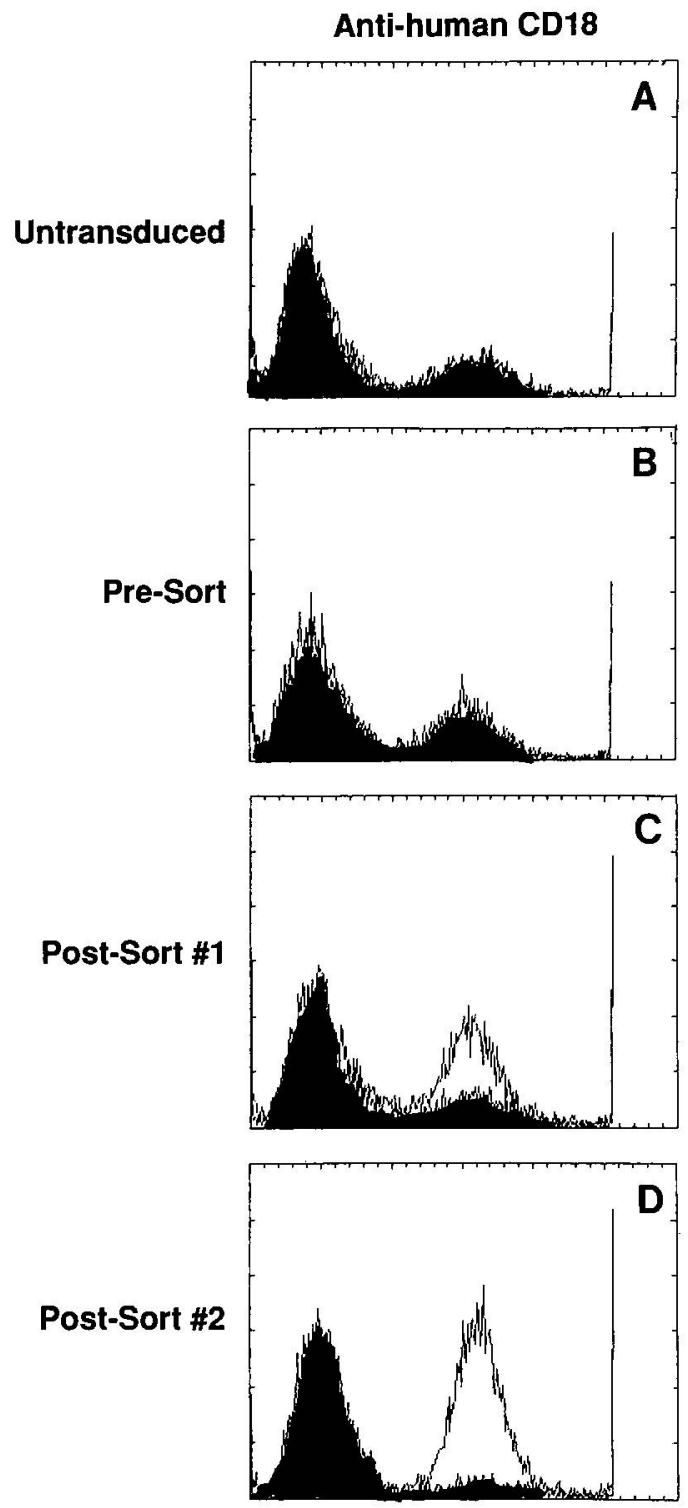

Immunofluorescence (log scale)

FIG. 2. Flow cytometric analysis of transduced lymphoblasts. BW5147 lymphoblasts were analyzed for cell-surface expression of human CD18 as described in Materials and Methods. Analyses included BW5147 lymphoblasts that were mock infected $(A)$ or infected with virus and analyzed directly $(B)$, after the first FACS (C) and after the second FACS (D). Data are presented as individual histograms of cell frequency versus immunofluorescence (log scale). The control antibody is shown shaded and the anti-human CD18 antibody is shown unshaded. 
immunofluorescence was performed as described (Wilson et al., 1990).

For two-color immunofluorescence, IB4 and M45q antibodies were biotinylated by standard procedures (Updyke and Nicolson, 1986), purified, and used as biotin conjugates. Cells $\left(10^{6} / \mathrm{ml}\right)$ were incubated with a rat anti-murine epitope antibody and a mouse anti-human epitope antibody, and subsequently stained with a goat anti-rat phycoerythrin (Southern Biotechnology, Birmingham, AL) and streptavidin-FITC. The cells were then fixed in $1 \%$ formaldehyde in phosphate-buffered saline (PBS) and analyzed for red and green fluorescence on a Coulter EPICS flow cytometer.

DNA and RNA Analysis: Total cellular DNA was isolated, restricted with $K p n$ I, transferred to a nylon filter and hybridized to a human CD18 probe as described previously (Wilson et al., 1990). Total cellular RNA was isolated, fractionated in a formaldehyde/agarose gel, and subjected to RNA blot analysis using a human CD18 cDNA probe as described previously (Wilson et al., 1990).

Immunoprecipitation: Lymphoblasts $\left(60 \times 10^{6}\right)$ were surface-labeled with ${ }^{125} \mathrm{I}$ (Amersham, Arlington Heights, IL) by the lactoperoxidase method (Kessler, 1981). Cells were washed free of excess ${ }^{125} \mathrm{I}$ in PBS, and lysed in NP-40 lysis buffer consisting of $1 \%$ NP-40, $1 \mathrm{~m} M$ PMSF, $1 \mu \mathrm{g} / \mathrm{ml}$ each of leupeptin, pepstatin $\mathrm{A}$, antipain, and chymostatin, $10 \mathrm{~m} M$ iodoacetamide, $1 \mathrm{~m} M$ EDTA, $150 \mathrm{mM} \mathrm{NaCl}$, and $10 \mathrm{~m} M$ Tris $\mathrm{pH} 8.0$ in distilled water (all reagents from Sigma, St. Louis, MO). The lysate was centrifuged in a microfuge and the supernatant was collected and precleared three times with $50 \mu$ l of Staph A (Bethesda Research Laboratories, Gaithersberg, MD). The lysate was then subjected to solid-phase immunoprecipitation (Tamura et al., 1984). Antibody $(100 \mu \mathrm{g} / \mathrm{ml}$ ) made to mouse immunoglobulin (for human CD18 immunoprecipitation) or rat immunoglobulin (for murine CD18 immunoprecipitation) was adhered to a polyvinyl chloride microtiter plate overnight at $4^{\circ} \mathrm{C}$. Excess antibody was removed with PBS, and a 1:10 dilution of ascites (anti-human CD18-TS1/18, provided by T. Springer, control antibodyp181), or neat tissue culture supernatant (anti-murine CD18M18/2.a.12.7, control antibody-M1/70.15.11.5), was then allowed to bind for $4 \mathrm{hr}$ at $4^{\circ} \mathrm{C}$. Wells were washed, blocked with $1 \%$ fetal calf serum in PBS, and incubated with ${ }^{125}$ I lysates at $4^{\circ} \mathrm{C}$ overnight. The lysates were carefully removed, the wells were washed, and the bound antigen was solubilized in SDS containing sample buffer. The samples were denatured by heating to $100^{\circ} \mathrm{C}$ for $5 \mathrm{~min}$ and then run on a nonreducing $8 \%$ SDS-PAGE. The gel was dryed onto filter paper and exposed to film.

\section{RESULTS}

\section{Human CD18 transducing retroviruses}

An ecotropic retroviral vector producer cell line was made with CD18 expressing retroviral vector used in our previous human complementation experiments (Wilson et al., 1990). The

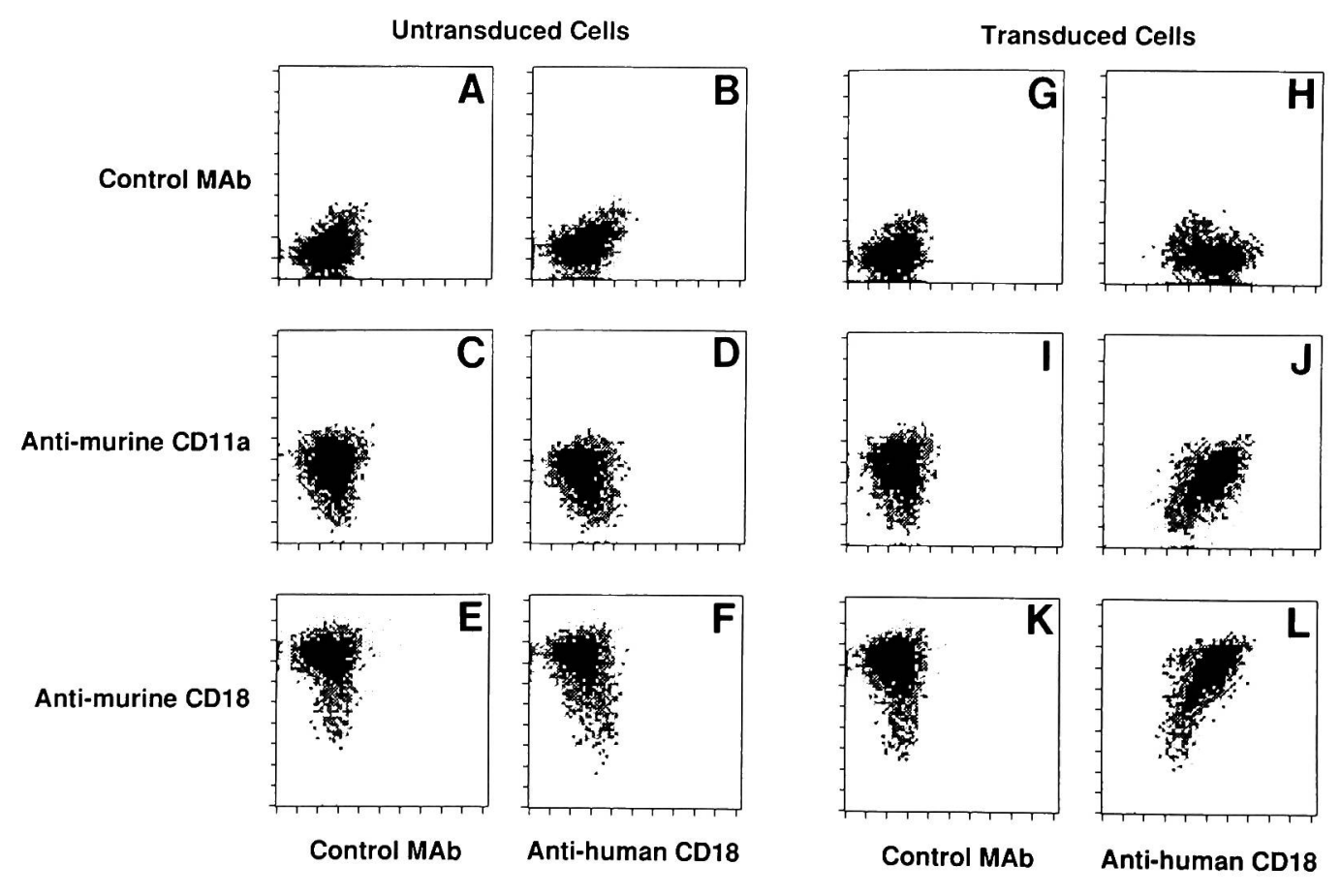

FIG. 3. Two-color flow cytometric analysis of untransduced and transduced, Post-Sort \#2 BW5147 cells. Cells were stained simultaneously with a biotin-conjugate formed with anti-human CD18 mAb (IB4) or control mAb (M45q) together with one of the following rat mAbs: anti-murine CD1 la, anti-murine CD18, or a control anti-murine mAb (Con Ab). Staining and flow cytometry are described in Materials and Methods. Red fluorescence is measured on the $y$ axis and green fluorescence is measured on the $x$ axis. Panels represent either untransduced cells or transduced cells (Post-Sort \#2) stained with mAbs directed against the various murine epitopes listed above. 
vector (called pEMO-CD18, depicted in Fig. 1A) contains a single LTR-based transcriptional unit that produces an unprocessed genomic transcript responsible for both transduction of $\mathrm{CD} 18$ and passage of the vector. Supernatants from 25 individual retroviral vector-producing cell lines were screened for titer of vector. Unrearranged proviral sequences, as measured by DNA blot analysis, were most abundant in NIH-3T3 cells infected with virus from clone 67-11 (0.1 proviral copies/cell, data not shown).

\section{Human CD18 expression in murine lymphoblasts}

Murine lymphoblasts were cocultivated with the retroviral vector producing cells for 2 days and subsequently expanded in culture. The lymphoblasts were analyzed by flow cytometry using an mAb specific for a human $\mathrm{CD} 18$ epitope. A small population of fluorescent cells (approximately $1 \%$ ) was noted in the lymphoblast cultures after cocultivation (Fig. 2B). This population of lymphoblasts was subjected to two sequential cycles of fluorescent activated cell sorting (FACS) using the human specific CD18 mAb in order to enrich for transduced cells. After two sterile sorts, a population of lymphoblasts that expressed high levels of human $\mathrm{CD} 18$ was obtained (Fig. 2C,D).

Populations of murine lymphoblasts that had been retrovirally transduced with a human CD18 gene and sorted for cell-surface expression of human CD18 were characterized for proviral DNA (Fig. 1B) and RNA (Fig. 1C). Molecular analyses were specifically performed on control lymphoblasts, and transduced lymphoblasts prior to FACS (Pre-Sort) and after one round (PostSort \#1) and two rounds (Post-Sort \#2) of FACS. Proviral DNA was undetectable $(<0.1$ copies/cell) in the presort population of transduced lymphoblasts (Fig. 1B, lane Pre-Sort). Enrichment of this population of cells for cell-surface expression of human CD18 was associated with the appearance and increase of unrearranged proviral DNA to approximately 1 proviral copy/ cell after two sterile sorts (Fig. 1B, lane Post-Sort \#2). Proviralderived CD18 RNA was detected after cocultivation in the presort population (Fig. 1C, lane Pre-Sort). The relative abundance of this transcript increased dramatically as the cells were enriched for cell-surface expression of human CD18 (Fig. 1C, lane Post-Sort \#2). The population of cells obtained after two sterile sorts with human CD18 mAb were subjected to further biochemical analyses of human $C D 18$ protein expression.

Murine lymphoblasts (untransduced and Post Sort \#2) were analyzed by two-color flow cytometry for the coexpression of human CD18 with murine CD18 and murine CD11a (Fig. 3). The untransduced murine lymphoblasts uniformly expressed high levels of endogenous CD18 and CD11a (Fig. 3C,E). Expression of human CD18 in the transduced Post-Sort \#2 population of cells had no apparent effect on the level of endogenous CD11a and CD18 protein (Fig. 3J,L).

It has been suggested that $\mathrm{CD} 18$ must associate with a CD11 subunit to be transported to, and positioned in, the plasma membrane (Marlin et al., 1986). We proposed, therefore, that human CD18 must be complexed with murine CD11a on the cell surface of the Post-Sort \#2 murine lymphoblasts. To prove this hypothesis, we performed the following immunoprecipitation experiments. Extracellular domains of membrane proteins were radiolabeled with ${ }^{125} \mathrm{I}$ and $\mathrm{CD} 11 / \mathrm{CD} 18$ complexes were isolated by immunoprecipitation with subunit and species-specific mAb (Fig. 4). Immunoprecipitation of extracts from untransduced cells revealed (i) no detectable bands over background when a human specific CD18 mAb was used (Fig. 4, lane A), and 2) bands that migrated with apparent molecular weights similar to murine CD18 $(95 \mathrm{kD})$ and murine $\mathrm{CD} 11 \mathrm{a}(180 \mathrm{kD})$ when a murine-specific mAb was used (Fig. 4, lane B). Immunoprecipitation of extracts from transduced Post-Sort \#2 cells with antibody to murine $\mathrm{CD} 18$ again demonstrated the endogenous CD18 and CD11 a bands (Fig. 4, lane F). Immunoprecipitation of these extracts with a human-specific $\mathrm{CD} 18 \mathrm{mAb}$ produced a band of $100 \mathrm{kD}$ representing human CD18 and a band of $180 \mathrm{kD}$ representing murine $\mathrm{CD} 1 \mathrm{la}$ (Fig. 4, lane E). The isolation of murine CD1 la with mAb to human CD18 suggests that the two glycoproteins are in close association with one another in the plasma membrane. The anomolous electrophoretic migration of human CD18 as compared to murine CD18 has been described previously (Sanchez-Madrid et al., 1982).

\section{Human CD18 expression in murine fibroblasts}

We next studied the expression of human CD18 in the nonhematopoietic cell line, NIH-3T3 fibroblasts. Immunocy-

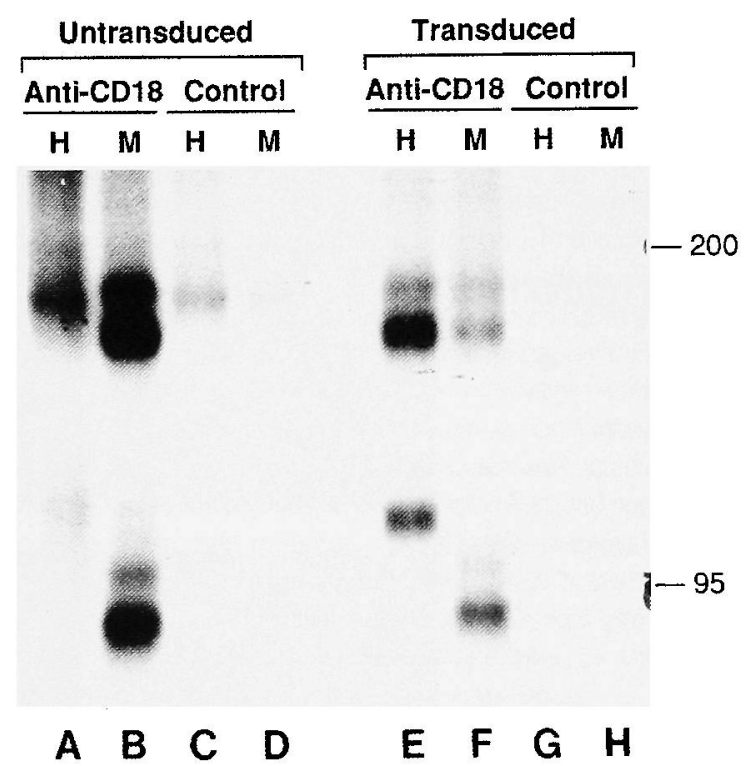

FIG. 4. Immunoprecipitation of ${ }^{125}$ I surface-labeled proteins. Proteins from untransduced and Post-Sort \#2 transduced BW5147 lymphoblasts were surface labeled and immunoprecipitated with anti-CD18 $\mathrm{mAb}$ or control $\mathrm{mAb}$ as described. $\mathrm{H}$ represents $\mathrm{mAbs}$ to human $\mathrm{CD} 18$ epitopes (including an isotype negative control) while $M$ represents mAbs to murine CD18 epitopes (including an isotype negative control). Molecular weight standards in kilodaltons are noted along the right border. Lysates of untransduced cells were precipitated with anti-CD18 to human (A) or mouse (B) or control mAb for human (C) or mouse (D). Lysates of transduced cells were precipitated with anti-CD18 to human $(\mathrm{E})$ or mouse $(\mathrm{F})$ or control $\mathrm{mAb}$ for human (G) or mouse $(\mathrm{H})$. 
tochemical analysis of NIH-3T3 cells transduced with CD18 retroviral vector revealed a subpopulation of cells with significant cytoplasmic staining (Fig. 5B). The efficiency of gene transfer estimated by immunocytochemistry (approximately $10 \%$ of all cells) was in good agreement with the estimate based on DNA blot analysis ( 0.1 proviral copies/cell). Flow cytometric analysis of this same population of cells with anit-human $\mathrm{CD} 18 \mathrm{mAb}$ failed to detect cell-surface fluorescence over background (Fig. 6B), suggesting that the human CD18 protein is not expressed on the plasma membrane. One explanation for these observations is that intracellular formation of a CD11/
CD18 heterodimer is necessary for efficient transport to the plasma membrane.

This hypothesis was directly tested by studying human CD18 expression in a clone of NIH-3T3 cells that express human CD11a. NIH-3T3 cells transfected with a CD1la expression vector demonstrate abundant intracellular $\mathrm{CD} 1$ la protein by immunocytochemistry (Fig. 5C) but no cell-surface CD11a protein by flow cytometry (Fig. 6C). However, coexpression of CD11a (Fig. 5E) and CD18 (Fig. 5F) in CD11a-expressing cells transduced with the CD18 retroviral vector resulted in cellsurface expression of both subunits (Fig. 6E,F).
Cell Line

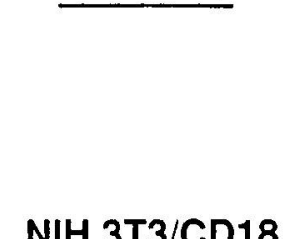

NIH 3T3/CD11a
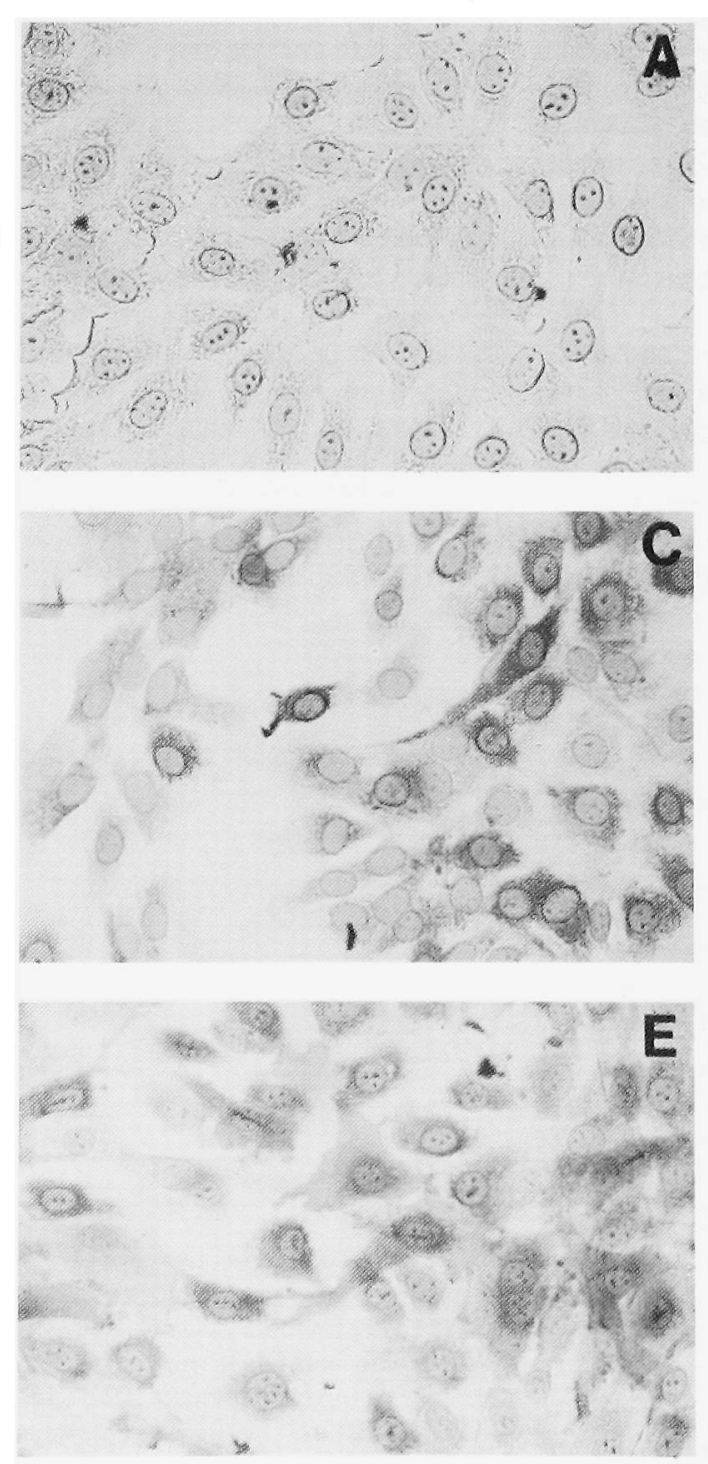
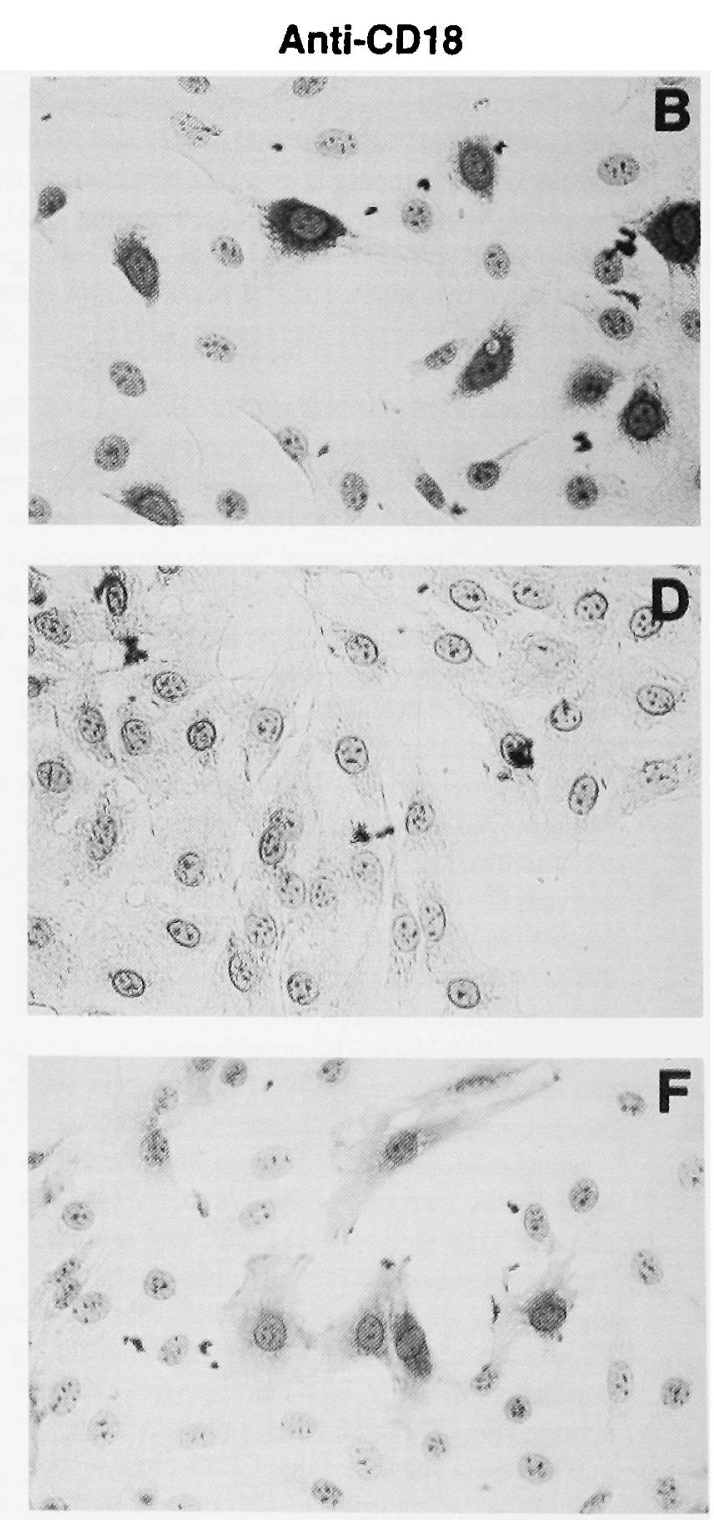

\section{NIH 3T3/CD11a/CD18}

FIG. 5. Immunochemistry of murine fibroblasts. Immunochemistry was performed as described in Materials and Methods Anti-human CD18 antibody is TS1/18, and the anti-human CD1 la antibody is TS1/22. Cells were counterstained with hematoxylin, and photomicrographs were taken with a Nikon microscope (original magnification, 400×). Panels represent NIH-3T3 cells transduced with a CD18-encoding retrovirus and stained with anti-CD11a (A) or anti-CD18 (B); CD1 la-expressing cell line (NIH-3T3/CD11a) stained with anti-CD11a (C) or anti-CD18 (D); and CD11a-expressing NIH-3T3 cell line transduced with the CD18-encoding retrovirus (NIH-3T3/CD11a/CD18) stained with anti-CD11a (E) or anti-CD18 (F). 

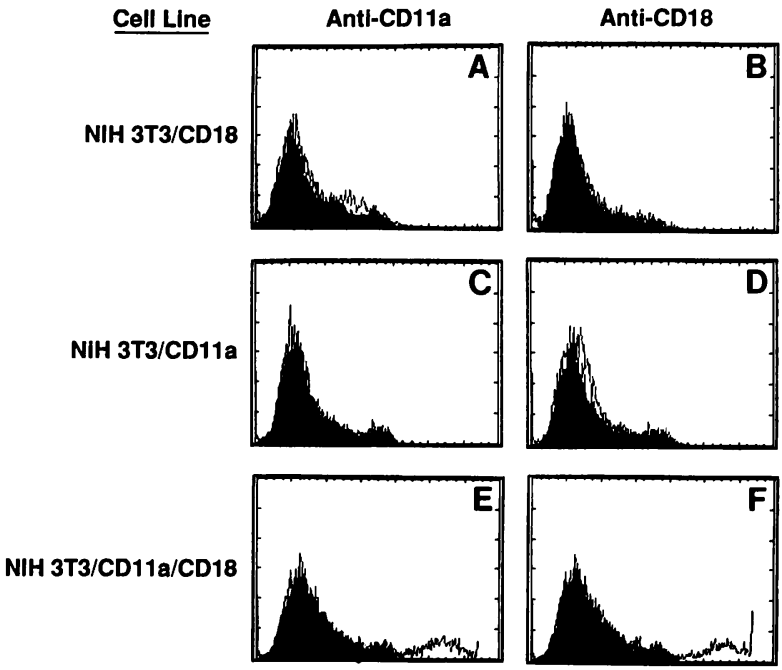

Immunofluorescence (log scale)

FIG. 6. Flow cytometric analysis of NIH-3T3 cells. Cells were stained as described in Materials and Methods. Panels represent a control antibody (shaded) over the antibody of interest (unshaded). Data are presented as individual histograms of cell frequency versus immunofluorescence (log scale). Antihuman CD18 antibody is TS1/18; anti-human CD11a antibody is TS1/22. Panels are representative of the following cells: $\mathrm{NIH}-3 \mathrm{~T} 3$ cells transduced with the CD18-encoding retrovirus and stained with anti-CD11a (A) or anti-CD18 (B); CD11aexpressing cell line (NIH-3T3/CD1 1a) stained with anti-CD11a (C) or anti-CD18 (D); and CD1la-expressing cell line transduced with $\mathrm{CD} 18$-encoding retrovirus and stained with antiCD1 la (E) or anti-CD18 (F).

\section{DISCUSSION}

LAD has many features that make it an excellent candidate for somatic gene therapy. It is an autosomal recessive disease caused by a defect in the gene that encodes CD18. We showed previously that the introduction of a normal CD18 gene into LAD-derived lymphocytes by retroviral-mediated gene transfer was sufficient to reconstitute normal adhesion-related functions (Wilson et al., 1990). The relative success of allogeneic bone marrow transplantation suggests that the appropriate target cell for gene transfer is the hematopoietic stem cell (LeDeist et al., 1989). Gene therapy, therefore, could be by a modification of autologous bone marrow transplantation. Finally, residual expression of $\mathrm{CD} 11 \mathrm{a} / \mathrm{CD} 18$ protein in homozygous-deficient patients is associated with a less severe phenotype, suggesting that partial genetic reconstition may be therapeutic (Anderson et al., 1985).

To better assess the therapeutic potential and risks of gene therapy for LAD, it is important to develop an in vivo animal model of human CD18 gene transfer. This would best be accomplished in the setting of an animal model of CD18 deficiency. Whereas LAD has been observed in a dog (Giger $e t$ al., 1987), since deceased, and in Holstein cattle (Kehrli et al.,
1990), neither animal offers a practical model for the preclinical testing of bone marrow gene replacement therapies. As an alternate, we propose a murine model in which a human CD18 gene is retrovirally transduced into bone marrow from a wildtype $\mathrm{C} 3 \mathrm{H} / \mathrm{HeJ}$ mouse, and lethally irradiated syngeneic recipients are reconstituted with the genetically modified bone marrow.

For this to be a valid model, it is important that human CD18 is appropriately expressed in murine leukocytes. Under normal conditions, the nascent CD18 peptide associates with CD11 subunit in the endoplasmic reticulum and the heterodimer is transported to secretory granules as well as the plasma membrane. $\mathrm{CD} 11 / \mathrm{CD} 18$ heterodimer formation is a prerequisite for normal processing. In this study, we tested the hypothesis that retroviral-transduced human CD18 will form heterodimers with murine CD1 la in a murine T-lymphoblast cell line, and that the chimeric heterodimer will be appropriately transported to the cell surface. Transduction of a human CD18 gene into murine lymphoblasts, in fact, resulted in high-level expression of the human subunit on the cell surface. Immunoprecipitation experiments suggested that, in this context, human CD18 was physically associated with murine CD11a, thereby confirming our original hypothesis. These results are in agremeent with previous studies of Springer, who analyzed CD11/CD18 expression in murine-human somatic cell hybrids (Marlin et al., 1986). In addition, we demonstrated that in fibroblast cell lines, both CD11a and CD18 expression are required for cell-surface $\mathrm{CD} 11 \mathrm{a} / \mathrm{CD} 18$ expression, but each protein could be detected singly by immunocytochemistry in the cytoplasm of cells that only express the transcript for one of the proteins. This suggests that CD18 cell-surface expression in vivo may not occur in cells that do not contain CD11 transcript.

Our results support the utility of the proposed in vivo animal model for studying human CD18 gene transfer in the context of a normal murine background. One advantage of the model is that transgene expression can be quantitatively measured in a limited number of hematopoietic cells by flow cytometry using humanspecific CD18 mAbs. Two-color flow cytometry affords the opportunity to study transgene expression in virtually any subpopulation of leukocytes. The spectrum and resolution of these analyses are limited only by the availability and specificity of mAbs to leukocyte antigens. Finally, the coexpression of human CD18/murine CD11 heterodimers with murine CD18/ murine CD11 heterodimers in the same cells will provide an opportunity to assess the level and regulation of transgene expression relative to endogenous gene expression.

\section{ACKNOWLEDGMENTS}

IB4 was provided by Dr. S.D. Wright (Rockefeller University, New York, NY). The authors thank Ms. C. Rogers and Ms. $\mathrm{K}$. Weber of the Simpson Memorial Institute Flow Cytometry facility for performing flow cytometric analysis. Supported by National Institutes of Health grant R01 CA39064 (R.F.T.), a development and feasibility project from the Multipurpose Arthritis Center at the University of Michigan (J.M.W.) and the Howard Hughes Medical Institute (J.M.W.). 


\section{REFERENCES}

ANDERSON, D.C., and SPRINGER, T.A. (1987). Leukocyte adhesion deficiency: An inherited defect in the MAC-1, LFA-1, and p150, 95 glycoproteins. Annu. Rev. Med. 38, 175-194.

ANDERSON, D.C., SCHMALSTEIG, F.C., FINEGOLD, M.J., HUGHES, B.J., ROTHLEIN, R., MILLER, L.J., KOHL, S., TOSI, M.F., JACOBS, R.L., WALDROP, T.C., GOLDMAN, A.S., SHEARER, W.T., and SPRINGER T.A. (1985). The severe and moderate phenotypes of heritable MAC-1, LFA-1 deficiency: their quantitative definition and relation to luekocyte dysfunction and clinical features. J. Inf. Dis. 152, 668-689.

BACK. A.L., KOWK, W.W., ADAM, M., COLLINS, S.J., and HICKSTEIN, D.D. (1990). Retroviral-mediated gene transfer of the leukocyte integrin CD18 subunit. Bio. Biophys. Res. Comm. 171, 787-795.

BIONDI, A., ROSSING, T.H., BENNETT, J., and TODD III, R.F. (1984). Surface membrane heterogeneity among human mononuclear phagocytes. J. Immunol. 132, 1237-1243.

DANOS, O., and MULLIGAN, R.C. (1988). Safe and efficient generation of recombinant retroviruses with amphotropic and ecotropic host ranges. Proc. Natl. Acad. Sci. USA 85, 6460-6464.

GIGER, U., BOXER, L.A., STMPSON, P.J., LUCCHESI, B.R., and TODD, R.F. III (1987). Deficiency of leukocyte surface glycoproteins Mol, LFA-1, and Leu M5 in a dog with recurrent bacterial infections: an animal model. Blood 69, 1622-1630.

KEHRLI, M.E., SCHMALSTEI, F.C., ANDERSON, D.C., VAN DER MAATEN, M.J., HUGHES. B.J., ACKERMANN, M.R., WILHELMSEN, C.L., BROWN, G.B., STEVENS, M.G., and WHETSTONE, C.A. (1990). Molecular definition of the bovine granulocytopathy syndrome: Identification of a deficiency of the Mac-1 (CD1lb/CD18) glycoprotein. Am. J. Vet. Res. 51, 18261836.

KESSLER, S.W. (1981). Use of protein A-bearing Staphylococci for the immunoprecipitation and isolation of antigens from cells. Methods Enzymol. 71, 442-458.

LARSON, R.S., CORBI, A.L., BERMAN, L., and SPRINGER, T.A. (1989). Primary structure of the leukocyte function-associated molecule- $1 \alpha$ subunit: An integrin with an embedded domain defining a protein superfamily. J. Cell Biol. 108, 703-712.

LE DEIST, F., BLANCHE, S., KEABLE, H. , GAUD, C., PHAM, H. . DESCAMP-LATSCHA, B., WAHN, V., GRISCELLI, C., and FISCHER, A. (1989). Successful HLA nonidentical bone marrow transplantation in three patients with the leukocyte adhesion deficiency. Blood 74, 512-516.

MARLIN, S.D., MORTON, C.C., ANDERSON, D.C., and SPRINGER, T.A. (1986). LFA-1 immunodeficiency disease: Definition of the genetic defect and chromosomal mapping of $\alpha$ and $\beta$ subunits of the lymphocyte function-associated antigen-1 (LFA-1) by complementation in hybrid cells. J. Exp. Med. 164, 855-867.

QUITSCHKE, W.W., LIN, ZE-YU, DEPON I-ZILLI, L., and PATERSON, B.M. (1989). The $\beta$ actin promoter: High levels of transcription depend upon a CCAAT binding factor. J. Biol. Chem. 264, 9539-9546.
RALPH, P.J. (1973). Retention of lymphocyte characteristics by myelomas and $\mathrm{O}^{+}$lymphomas: Sensitivity of hydrocortisone and phytohemagglutin. Immunology 110, 1470-1475.

SANCHEZ-MADRID, F., KRENSKY, A.M. WARE, C.F. ROBBINS, E. STROMGINER, J.L., BURAKOFF, S.J., and SPRINGER, T.A. (1982). Three distinct antigens associated with human T-lymphocyte-mediated cytolysis: LFA-1, LFA-2, and LFA-3. Proc. Natl. Acad. Sci. USA 79, 7489-7493.

SANCHEZ-MADRID, F., SIMON, P., THOMPSON, S., and SPRINGER, T.A. (1983). Mapping of antigenic and functional epitopes on the $\alpha$ - and $\beta$-subunits of two related mouse glycoproteins involved in cell interactions, LFA-1 and MAC-1. J. Exp. Med. 158, 586-602.

SPRINGER, T.A., GALFRE, G., SECHER, D.S., and MILSTEIN, C. (1978). Monoclonal xenogeneic antibodies to murine cell surface antigens: Identification of novel leukocyte differentiation antigens. Eur. J. Immunol. 8, 539-551.

SPRINGER, T.A., THOMPSON, W.S., MILLER, L.J., SCHMALSTEIN, F.C., and ANDERSON, D.C. (1984). Inherited deficiency of the MAC-1, LFA-1, and p150,95 glycoprotein family and its molecular basis. J. Exp. Med. 160, 1901-1918.

TAMURA, G.S., DALEY, M.O., GALATIN, W.M., MCGRATH, M.S., WEISSMAN, I.L., and PILLEMER, E.A. (1984). Isolation of molecules recognized by monoclonal antibodies and antisera: the solid phase immunoisolation technique. Anal. Biochem. 136, 458 464.

TODD R.F., III, and FREYER, D.R. (1988). The CD11/CD18 leukocyte glycoprotein deficiency. Hem./Oncol. Clin. N. Am., 2, 13-31.

UPDYKE, T.V., and NICOLSON, G.L. (1986). Immunoaffinity isolation of membrane antigens with biotinylated monoclonal antibodies and streptavidin-agarose. Methods Enzymol. 121, 717-725.

WILSON, J.M., JEFFERSON. D.M. CHOWDHURY, J.R., NOVIKOFF, P.M., JOHNSTON, D.E., and MULLIGAN, R.C. (1988). Retrovirus mediated transduction of adult hepatocytes. Proc. Nat. Acad. Sci. USA 85, 3014-3018.

WILSON, J.M., PING, A.J., KRAUSS, J.C., MAYO-BOND, L., ROGERS, C.E., ANDERSON, D.C., and TODD, R.F., III. (1990). Correction of CD18 deficient lymphocytes by retrovirus mediated gene transfer. Science 248, 1413-1416.

WRIGHT, S.D., RAO, P.E., VAN VOORHIS, W.C., CRAIGMYLE, L.S., LIDA, K. TALLE, M.A., WESTBERG, E.F., GOLDSTEIN, G., and SILVERSTEIN, S.C. (1983). Identification of the C3bi receptor of human monocytes and macrophages by using monoclonal antibodies. Proc. Natl. Acad. Sci. USA 80, 5699-5703.

Address reprint requests to: Dr. J.M. Wilson Departments of Internal Medicine and Biological Chemistry MSRB 2 Room 4554

University of Michigan Ann Arbor, MI 48109-0650

Received for publication June 3, 1991; accepted after revision July 12,1991 . 
This article has been cited by:

1. Raymond W. Wilson, Tohru Yorifuji, Isabel Lorenzo, Wayne Smith, Donald C. Anderson, John W. Belmont, Arthur L. Beaudet. 1993. Expression of Human CD18 in Murine Granulocytes and Improved Efficiency for Infection of Deficient Human LymphoblastsExpression of Human CD18 in Murine Granulocytes and Improved Efficiency for Infection of Deficient Human Lymphoblasts. Human Gene Therapy 4:1, 25-34. [Abstract] [PDF] [PDF Plus] 